\title{
THE GENETICS OF GOUT AND HYPERURICEMIA-AN ANALYSIS OF NINETEEN FAMILIES
}

\author{
By C. J. SMYTH,1 C. W. COTTERMAN, AND R. H. FREYBERG 2 \\ (From the Rackham Arthritis Unit ${ }^{3}$ and the Heredity Clinic, ${ }^{3}$ University of Michigan, \\ Ann Arbor)
}

(Received for publication February 17, 1948)

At an earlier period, when less confidence was generally held for the gene theory of inheritance, it was natural to insist that any genotype postulated to explain a given disease or abnormality should be perfectly correlated with this disease. When it became increasingly realized that this supposition was unnecessary, a fruitful method of study became available for those diseases showing only occasional evidence of inheritance. By assuming that a given genotype might cause only a portion of its possessors to develop the trait in question, an irregular pattern of inheritance was often found to be adequately explained on the basis of a single gene hypothesis. However, merely to satisfy the requirements of a formal theory would, in general, have represented but little gain. A more important result was that increased attention was now accorded those individuals who, although lacking the disease or abnormality, were evidently carriers of the genetic factor. As a consequence, several important hereditary diseases are now known to be frequently replaced by detectable subclinical manifestations or "carrier states," and these conditions have been recently discussed in extensive reviews $(1,2)$.

In the field of metabolic disorders, Garrod (3) was among the first to emphasize this point of view, notably with respect to gout. He suggested that this disease would probably be found to be due to a dominant Mendelian factor which expresses itself fairly regularly in hyperuricemia, but only occa-

\footnotetext{
1 Now Medical Director, W. J. Seymour Division, Wayne County General Hospital, Eloise, Mich., and Instructor, Department of Medicine, Wayne University Medical School, Detroit, Mich.

2 Now Associate Professor of Clinical Medicine, Cornell University Medical School, and Director, Department of Internal Medicine, Hospital for Special Surgery, New York City.

3 Both of these research units are supported by grants from the Horace H. Rackham School of Graduate Studies, University of Michigan.
}

sionally in gouty arthritis. A number of studies (4-7) have since shown that hyperuricemia without arthritis is indeed a common finding among the relatives of gouty patients. The most extensive studies thus far reported are those of Talbott and of Stecher and Hersh. Talbott (5) investigated 136 relatives of 27 patients and found hyperuricemia (serum uric acid exceeding $6 \mathrm{mgm}$. per cent) in 27 male and seven female relatives. Unfortunately this excellent body of data has thus far been published only in an incomplete form which does not permit of statistical or genetic analysis. A biochemical study of 30 gouty families has also been reported in abstract form by Stecher and Hersh (7).

The present paper presents an analysis of 19 gouty families studied at the Arthritis Clinic of the University of Michigan Hospital during the years 1938 to 1942 . Two of these families have been previously reported by Smyth and Freyberg in a paper (6) which will serve to describe more fully the methods used in the investigation. Although these two families demonstrated a marked hereditary tendency in hyperuricemia, the question was left unsettled as to whether all cases of gout can be encompassed in a single genetic theory. The present analysis was carried out in 1942. The results showed that the hypothesis of a dominant autosomal gene for hyperuricemia will satisfactorily explain the variations in serum urate concentrations found among an unselected series of families, but only after allowance is made for certain other factors influencing the level of serum urate in these relatives.

\section{DESCRIPTION OF DATA}

The 19 families which form the basis of this report constitute Kindreds 1109 to 1127 in the files of the University of Michigan Heredity Clinic. In this paper the families are designated by the letters $A$ to $S$, respectively. The propositus ("index case" or original patient) is in each case a male patient showing clinical, biochemical 
and, in most cases, radiological evidence of gouty arthritis. A total of 87 relatives was studied and the data concerning these individuals are incorporated on the pedigree diagrams of Figure 1. In general, the pedigrees show only those individuals whose bloods were tested for serum urate, but a few additional members have been portrayed in order to define relationships between ex- amined members. The pedigrees are therefore incomplete in some cases in the sense that all brothers and sisters of certain individuals are not shown.

In almost all cases the blood samples were obtained after a fast of eight to 12 hours. The blood was allowed to clot under oil, and uric acid determinations were made on the serum using the indirect method of

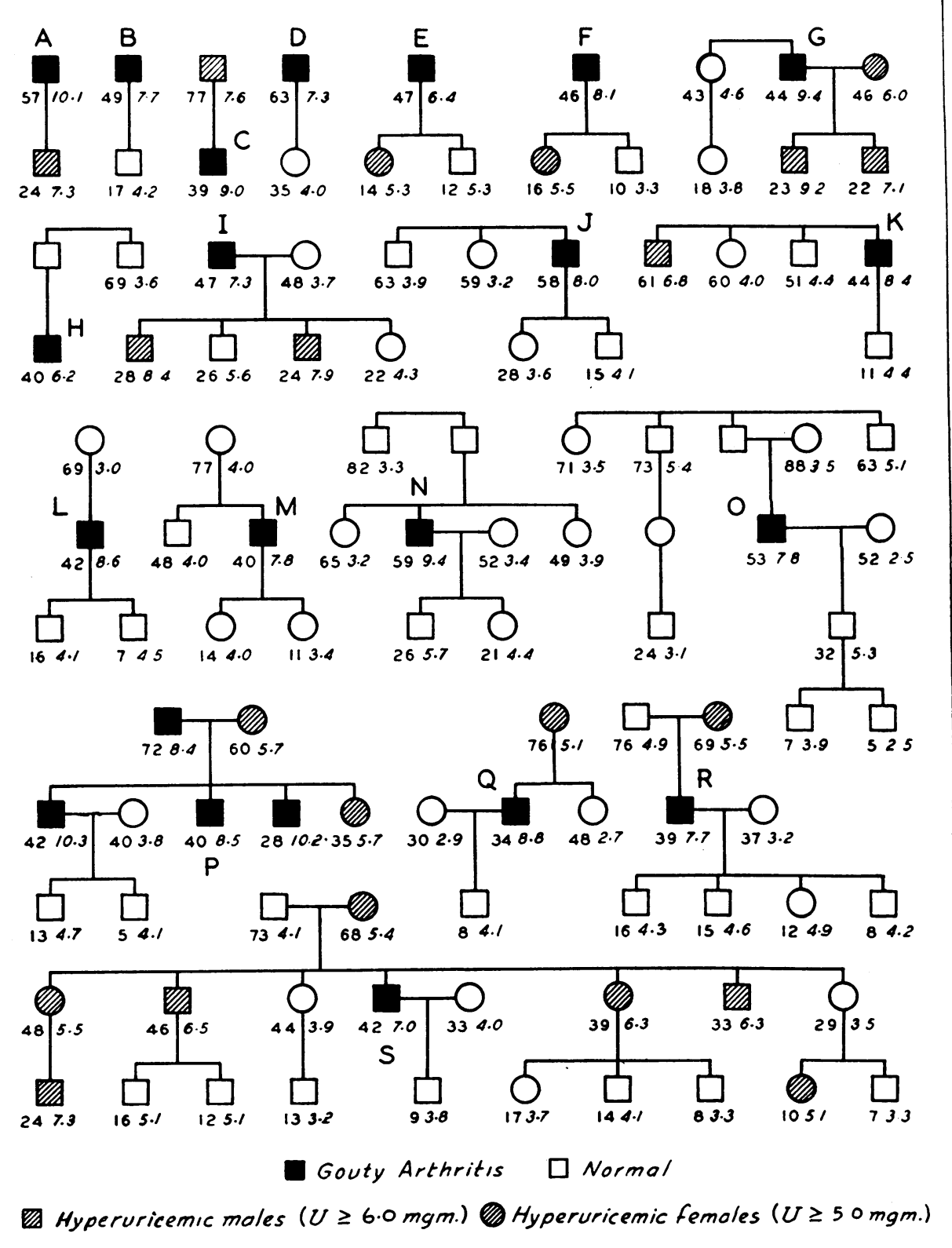

Fig. 1. Pedigrees of 19 Gouty Male Patients

The 19 families are designated by letters, A-S, placed nearest the propositus or original patient in each case. Figures below the pedigree symbols represent age $(T)$ in years, followed by serum urate concentration $(U)$ in $\mathrm{mgm}$. per cent. 
Folin (8). The italicized figures beneath the pedigree symbols in Figure 1 indicate the serum urate levels found for each individual, expressed in milligrams uric acid per 100 cc. of serum. In most cases only one determination was obtained for each relative, but a few of the recorded figures represent averages of several determinations.

The two families previously reported (6) are identical with families $I$ and $P$ in this paper. In the latter family, the propositus, who is represented by the symbol nearest the letter $P$ in Figure 1, was found to have two gouty brothers and a gouty father. No other relatives belonging to any kindred were known to have a history suggesting gout, and none was found to have tophi. The 19 patients were selected for study solely on the basis of the availability of their relatives, and blood samples were secured on all individuals who were willing to cooperate. It therefore seems likely that the resulting data should provide unbiased estimates of the frequency of hyperuricemia among relatives of any given class.

\section{REGRESSION ANALYSIS}

Before examining the data from the point of view of a specific genetic theory, we have analyzed the variation in serum urate levels by means of general statistical methods. This was done in order to ascertain (1) whether there was evidence of genetic variability of any kind, (2) whether age and sex were additional factors influencing the level of serum urate, and (3) whether there was any justification for dividing the relatives into "normal" and "hyperuricemic" groups in the hope that these would correspond to two specific genotypes.

In addition to the serum uric acid concentration $(U)$, Figure 1 also supplies information on the age $(T)$, sex $(S)$, and mode of relationship $(R)$ of each relative to the gouty propositus. As a preliminary procedure, we chose to investigate the influence of $R, S$, and $T$ on $U$ by means of multiple regression statistics (cf. Snedecor [9]). Instead of dividing the data into various sex and relationship classes, we have assigned to each relative a score for sex, $S=0$ for males and $S=1$ for females, and have used the coefficient of relationship (10) as a measure $(R)$ of the degree of relationship between the propositus and each of his relatives.

It will suffice to explain here that the coefficient of relationship $(R)$ is a measure of the degree of genetic resemblance between any two relatives, and its value varies from $R=0$ for unrelated individuals, to $R=1$ for "identical twins." For parents, sibs and children of the propositi $R=0.50$, while for grandparents, aunts, uncles, nieces, nephews and grandchildren $R=0.25$. All relatives in the present series of pedigrees fall into one or the other of these two degrees of relationship, except for one first cousin once-removed of patient $\mathrm{O}$ whose coefficient of relationship to $O$ is $R=0.0625$. Now, for any autosomal gene present in a gouty patient, the probability that this gene will also be present in a given relative is equal to his or her coefficient of relationship to the patient (10). Therefore, since we shall later wish to test the hypothesis of a dominant autosomal gene for hyper- uricemia, the use of $R$ is appropriate in the present problem.

The data of Figure 1 may thus be summarized by tabulating for each relative the four variables $R, S, T$ and $U$. For example, for the uncle of patient $H$, Figure 1 shows that

$$
R=0.25, S=0, T=69 \mathrm{yr} ., U=3.6 \mathrm{mgm} \text {. per cent. }
$$

The wives of seven propositi and of one gouty brother of patient $\mathbf{P}$ were also tested, and these unrelated individuals are included in the analysis as "relatives" of degree $R=0$. Thus, for the wife of patient $Q$, Figure 1 shows that

$$
R=0, S=1, T=30 \text { yr., } U=2.9 \text { mgm. per cent. }
$$

In order to discover whether age $(T)$, sex $(S)$ and degree of genetic relationship $(R)$ significantly affect the uric acid level in relatives of gout patients, we applied the method of multiple regression analysis (9). A regression equation of the usual form,

$$
U^{\prime}=a+b R+c S+d T,
$$

was fitted to the data on all 87 relatives. In this equation $U^{\prime}$ is the predicted uric acid level, $a$ is a basic level of serum urate (the amount to be expected in an unrelated male at birth, i.e., an individual having $R=S=T=0$ ), and $b, c$ and $d$ are the "partial regression coefficients," that is, the amounts by which the urate level changes with unit increases in $R, S$ and $T$, respectively. The derivation of the constants $a, b, c$ and $d$ was carried out by means of the usual methods of regression analysis (9), except that the sums of squares and products of deviations in the four variables were computed from the means of the 19 sets of relatives belonging to the separate pedigrees, rather than from the general mean of all 87 relatives. In this way we obtained the following equation for predicting the uric acid level of a relative from the age, sex and degree of relationship to the gouty patient:

$$
\begin{aligned}
U^{\prime}=3.5085+3.2205 R-0.94433 S & \\
& +0.011808 T \text { mgm. per cent. }
\end{aligned}
$$

The tests of significance of the deviations of the three regression coefficients from zero were carried out on the corresponding standard partial regression coefficients (9) (Table I). Those for sex and degree of relationship are

\begin{tabular}{|c|c|c|c|}
\hline $\begin{array}{l}\text { Partial regression of } U \\
\text { (serum urate level) on: }\end{array}$ & $\begin{array}{l}\text { Regression } \\
\text { coefficient, } \\
\beta\end{array}$ & $\begin{array}{l}\text { Stándard } \\
\text { error, } \\
s \beta\end{array}$ & $t=\beta / s_{\beta}$ \\
\hline $\begin{array}{l}R \text { (degree of relationship) } \\
S \text { (sex) } \\
T \text { (age) }\end{array}$ & $\begin{array}{l}+0.37022 \\
-0.34147 \\
+0.19079\end{array}$ & $\begin{array}{l} \pm 0.10668 \\
\pm 0.11194 \\
\pm 0.11126\end{array}$ & $\begin{array}{l}3.470^{*} \\
3.051^{*} \\
1.715\end{array}$ \\
\hline
\end{tabular}
statistically significant at the 1 per cent probability level, whereas the positive regression of uric acid concentration on age falls short of the 5 per cent level of significance.

TABLE I

* Highly significant value for 65 degrees of freedom. 
Relationship: The coefficient $b=+3.2205$ may be interpreted as meaning that an identical twin $(R=1)$ of a gouty patient would be expected to have a uric acid concentration about $3.2 \mathrm{mgm}$. higher than that of an unrelated person $(R=0)$, as judged from the average excesses of $0.5 b=1.6 \mathrm{mgm}$. for parents, sibs and children, and $0.25 b=0.8 \mathrm{mgm}$. for aunts, nieces, grandchildren, etc. This tendency for the uric acid level to increase with increased relationship to gouty patients may be taken as a general indication of heredity, or, at least, of certain factors operating within kindreds in a manner simulating inheritance.

Sex: The coefficient $c=-0.94433$ shows that females $(S=1)$ average about $1 \mathrm{mgm}$. less uric acid than male relatives $(S=0)$ of the same age and degree of relationship to gouty patients. This difference compares favorably with that found by other investigators for unselected adult males and females. We have calculated the means and standard deviations of $U$ from data presented by Jacobson (4), Br $\phi$ chner-Mortensen (11), and Bulger and Johns (12). Although these workers employed different biochemical procedures, the results $(\mathrm{Ta}$ ble II) agree in showing a significantly higher mean uric acid value in males. The variances or standard deviations of $U$, however, are not significantly different in the two sexes. It is therefore apparent that any genetic theory proposed for hereditary hyperuricemia must take this sex difference into account, and that if relatives of gouty patients are to be classified as "normal" or "hyperuricemic," different critical levels of serum urate will probably have to be adopted for the two sexes. These levels may of necessity be different for various investigators, owing to systematic differences in biochemical techniques.

Age: The coefficient $d=+0.011808$ shows that uric acid levels increase by about $0.01 \mathrm{mgm}$. per cent per year for the whole of our data, but the increase is not sufficient to establish itself as significantly greater than zero.
TABLE II

Published studies of blood uric acid concentration in unselected adult males and females

\begin{tabular}{|c|c|c|c|}
\hline Investigator & $\underset{n}{\text { Number }}$ & $\underset{\bar{u}}{\operatorname{Mean}}$ & $\begin{array}{l}\text { Standard } \\
\text { deviation, } s\end{array}$ \\
\hline $\begin{array}{r}\text { Br } \phi \text { chner-Mortensen (11) } \\
\text { Males: } \\
\text { Females: }\end{array}$ & $\begin{array}{l}25 \\
25\end{array}$ & $\begin{array}{l}m g m . \% \\
7.62 \\
6.35\end{array}$ & $\begin{array}{r}m g m . \% \\
0.917 \\
1.057\end{array}$ \\
\hline Difference: & & $1.27^{*}$ & -0.140 \\
\hline $\begin{array}{l}\text { Males: } \\
\text { Females: }\end{array}$ & $\begin{array}{l}63 \\
37\end{array}$ & $\begin{array}{l}4.4 \\
4.0\end{array}$ & $\begin{array}{l}1.079 \\
1.052\end{array}$ \\
\hline Difference: & & $0.4^{*}$ & 0.027 \\
\hline $\begin{array}{r}\text { Bulger \& Johns (12) } \\
\text { Males: } \\
\text { Females: }\end{array}$ & $\begin{array}{l}62 \\
41\end{array}$ & $\begin{array}{l}4.49 \\
3.59\end{array}$ & $\begin{array}{l}0.974 \\
1.098\end{array}$ \\
\hline Difference: & & $0.90^{*}$ & -0.124 \\
\hline
\end{tabular}

* Highly significant difference $(P<.01)$.

The total correlation coefficient for age and serum urate concentration is +0.222 for the 48 male relatives and -0.098 for the 39 female relatives, and these values are likewise non-significant. The data therefore fail to establish any definite relationship of serum urate concentration to age as measured by linear regression over the entire age range. However, the scatter diagram for male relatives (Figure 2) shows that none of the 22 boys below 18 years of age had serum urate exceeding $6 \mathrm{mgm}$. per cent, whereas the 26 older males are equally divided at this level (Table III). The probability of this extreme association in sampling from a population in which hyperuricemia is equally common in the two age groups is only $35 ! 26 ! / 48 ! 13 !=0.00005$.

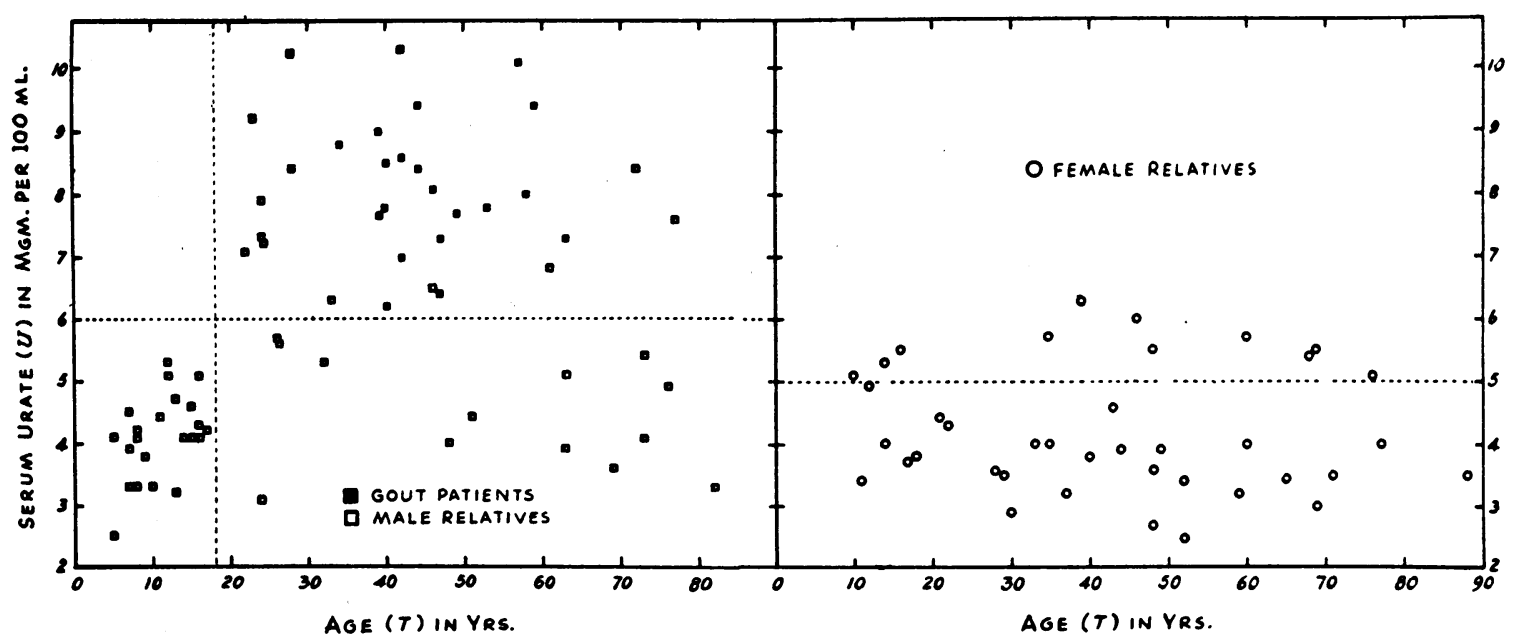

Fig. 2. Distribution of Gouty Patients and Relatives with Respect to Age and Serum URATE Concentration 
TABLE III

\begin{tabular}{c|c|c}
\hline Male relatives & Under 18 yr. & Over 18 yr. \\
\hline $\begin{array}{c}\text { Hyperuricemic } \\
(U>6 \text { mgm. })\end{array}$ & 0 & 13 \\
\hline $\begin{array}{c}\text { Normal } \\
(U<6 \text { mgm. })\end{array}$ & 22 & 13 \\
\hline
\end{tabular}

We have interpreted this result to mean that the serum urate concentration is probably little, if at all, elevated in young males who possess the genetic factor or factors for hyperuricemia and gout. However, an alternative explanation should be mentioned at this point. It will be seen from Figure 1 that all but four of the 22 males below 18 years of age are sons of gouty or hyperuricemic males, or sons of such sons. The absence of hyperuricemia in this group might therefore suggest that males do not inherit factors for hyperuricemia from their fathers. This would suggest sex-linkage, but the whole of the information available does not support this view, as will be shown in a later section.

\section{ANALYSIS OF VARIANCE}

Although sex and degree of relationship to gouty patients have been shown to be significant factors affecting the level of serum urate, the data give evidence of certain kinds of heterogeneity. In Table IV an analysis of

TABLE IV

Analysis of variance for kindreds

\begin{tabular}{l|c|c|c}
\hline \hline Source of variation & $\begin{array}{c}\text { Degrees } \\
\text { of } \\
\text { freedom }\end{array}$ & $\begin{array}{c}\text { Sum } \\
\text { of } \\
\text { squares }\end{array}$ & $\begin{array}{c}\text { Mean } \\
\text { square }\end{array}$ \\
\hline $\begin{array}{l}\text { Between kindred means } \\
\text { Within kindreds }\end{array}$ & 18 & $\begin{array}{c}88.0338 \\
68\end{array}$ & $\begin{array}{l}444.3202 \\
2.1224\end{array}$ \\
\hline Total & 86 & 232.3540 & \\
\hline
\end{tabular}

* Highly significant difference.

variance (9) is set forth for the variations in urate concentrations within and between kindreds. A comparison of the mean squares for these components $(F=4.8908$ / $2.1224 \doteq 2.3044)$ shows that there are significant differences among the means of relatives belonging to different pedigrees. When allowance is made for the fact that these 19 sets of relatives differ in their composition with respect to age, sex, and degree of relationship, we obtain, through the use of regression equations (9), the analysis shown in Table V. The variance among adjusted means of kindreds is now even greater in relation to the residual variation within kindreds, and is again highly significant $(F=4.8166 / 1.5376=3.1325)$.

It therefore appears that serum urate levels in relatives of different gouty patients vary to a degree greater than one would expect by chance if such kindreds were segregating for the same genetic factor producing hyper- uricemia and gout. Such a result would be anticipated if (1) some of the patients had been incorrectly diagnosed as gouty arthritis, or, what is practically the same, if gout, as diagnosed, were more than a single genetic entity. It would also be explained if (2) environmental factors or modifying genetic factors (in addition to those of age and sex) were unequally distributed among different gouty kindreds. Also the heterogeneity might appear, even in the absence of (1) and (2), if (3) matings between two hyperuricemic individuals occurred in

TABLE $\mathrm{V}$

Analysis of variance for kindreds after adjustment for age, sex and relationship variations

\begin{tabular}{l|c|c|c}
\hline Source of variation & $\begin{array}{c}\text { Degrees } \\
\text { of } \\
\text { freedom }\end{array}$ & $\begin{array}{c}\text { Sum } \\
\text { of } \\
\text { squares }\end{array}$ & $\begin{array}{c}\text { Mean } \\
\text { square }\end{array}$ \\
\hline $\begin{array}{c}\text { Between adjusted means of } \\
\text { kindreds }\end{array}$ & 18 & 86.6996 & $4.8166^{*}$ \\
$\begin{array}{c}\text { Deviations from regression } \\
\text { within kindreds }\end{array}$ & 65 & 99.9431 & 1.5376 \\
\hline Total & 83 & 186.6427 & \\
\hline
\end{tabular}

* Highly significant difference.

some kindreds but not in all. Some further evidence in favor of (1) and (3) will be discussed in the following section.

Table VI gives the mean uric acid levels for relatives belonging to various age, sex and relationship classes. It is evident that the serum urate level has a higher average value among relatives of degree $R=0.50$ than among relatives of degree $R=0.25$, and this is true for both sexes and both age groups. However, the excess is greater in adults than in children and also much greater in males than in females. These discrepancies are statistically significant, and we may conclude that the genetic factor or factors which lead to an elevation in serum urate have a greater average effect in males than in

\section{TABLE VI}

Mean uric acid levels for relatives of various age, sex and relationship classes (Frequency in each class given in parentheses)

\begin{tabular}{|c|c|c|c|c|}
\hline $\begin{array}{l}\text { Male relatives } \\
\text { of degree: }\end{array}$ & Under 18 yr. & Over 18 yr. & All & ges \\
\hline $\begin{array}{l}R=.0625 \\
R=.25 \\
R=.50\end{array}$ & $\begin{array}{ll}\overline{3.93} & (10) \\
4.24 & (12)\end{array}$ & $\begin{array}{ll}3.10 & (1) \\
4.94 & (5) \\
6.70 & (20)\end{array}$ & $\begin{array}{l}3.10 \\
4.27 \\
5.78\end{array}$ & $\begin{array}{l}(1) \\
(15) \\
(32)\end{array}$ \\
\hline All males & $4.10 \quad(22)$ & $6.22 \quad(26)$ & 5.25 & (48) \\
\hline $\begin{array}{l}\text { Female relatives } \\
\text { of degree: }\end{array}$ & Under $18 \mathrm{yr}$. & Over $18 \mathrm{yr}$. & \multicolumn{2}{|c|}{ All ages } \\
\hline $\begin{array}{l}R=0 \\
R=.25 \\
R=.50\end{array}$ & $\begin{array}{ll}- & (0) \\
4.40 & (2) \\
4.62 & (5)\end{array}$ & $\begin{array}{lr}3.69 & (8) \\
3.65 & (2) \\
4.32 & (22)\end{array}$ & $\begin{array}{l}3.69 \\
4.02 \\
4.37\end{array}$ & $\begin{array}{r}(8) \\
(4) \\
(27)\end{array}$ \\
\hline All females & 4.56 & $4.12 \quad(32)$ & 4.20 & (39) \\
\hline
\end{tabular}


females. The classification of relatives into normal and hyperuricemic groups should therefore prove to be a more difficult task in the case of females.

\section{HYPOTHESIS OF A DOMINANT GENE}

So far our analysis has shown merely that some genetic factors in addition to sex may be assumed to account for variations in serum uric acid levels among relatives of gouty patients. Whether it would be profitable to carry this analysis further, by postulating a single gene for hyperuricemia, depends largely on the form of the distribution of urate levels found among the 87 relatives. For example, if instead of blood uric acid levels we had recorded the statures of the relatives of $19 \mathrm{ex}-$ ceptionally tall men, we would have anticipated results very similar to those described above. Males, in general, would be taller than females; the statures would increase with increased relationship to the tall men; and older relatives would be found to be taller than younger ones, although the latter fact might escape detection in a regression equation if adequate numbers of the younger relatives had not been recorded. However, the statures would probably be normally distributed about the means for any age and sex group. Hence, any subdivision of the relatives into "tall" and "normal" would be quite arbitrary, and the hereditary component in stature would be more readily explained on the basis of an inter-play of a large number of genetic factors.

On the other hand, if most of the variability in serum urate levels were determined by a single gene for hyperuricemia, we should expect a bimodal frequency distribution of these levels provided that the separation between the normal and abnormal genotypes were not obscured by relatively large non-genetic variations. Now, it is known that the fasting serum uric acid level is far from a fixed individual characteristic, even at a constant age. Various environmental factors, in addition to technical errors, are thought to be effective in producing marked fluctuations in serum urate determinations when tests are made in single subjects over short intervals of time.

Despite these important individual variations which might be expected to account for the misclassification of some of the relatives, the frequency diagrams of Figure 3 do suggest a bimodal distribution of $U$ among relatives of both sexes, and we have considered it of interest to classify the relatives on the basis of the minimum points in these distributions, viz., $6.0 \mathrm{mgm}$. per cent in males and $5.0 \mathrm{mgm}$. per cent in females. The former level agrees with the criterion for pathological hyperuricemia commonly adopted by workers using the Folin procedures. It also agrees with the lower limit found in most cases of gouty arthritis, as is shown by our own data (Figure 3 ). The lowering of the critical level to $5.0 \mathrm{mgm}$. per cent in females is suggested by the frequency diagram for females, and this accords with the information cited above from general chemical studies (Table II), namely, that the distributions for the two sexes have approximately equal variances with a mean difference of about $1.0 \mathrm{mgm}$. per cent.

Using these critical levels 10 of the 48 male relatives and 11 of the 39 females are classed as hyperuricemic. These individuals are shown in Figure 1 by shaded squares and circles, and it is seen that the distribution of hyperuricemic individuals in the 19 pedigrees conforms rather closely with what one might expect if such kindreds were segregating for a dominant autosomal gene for hyperuricemia.
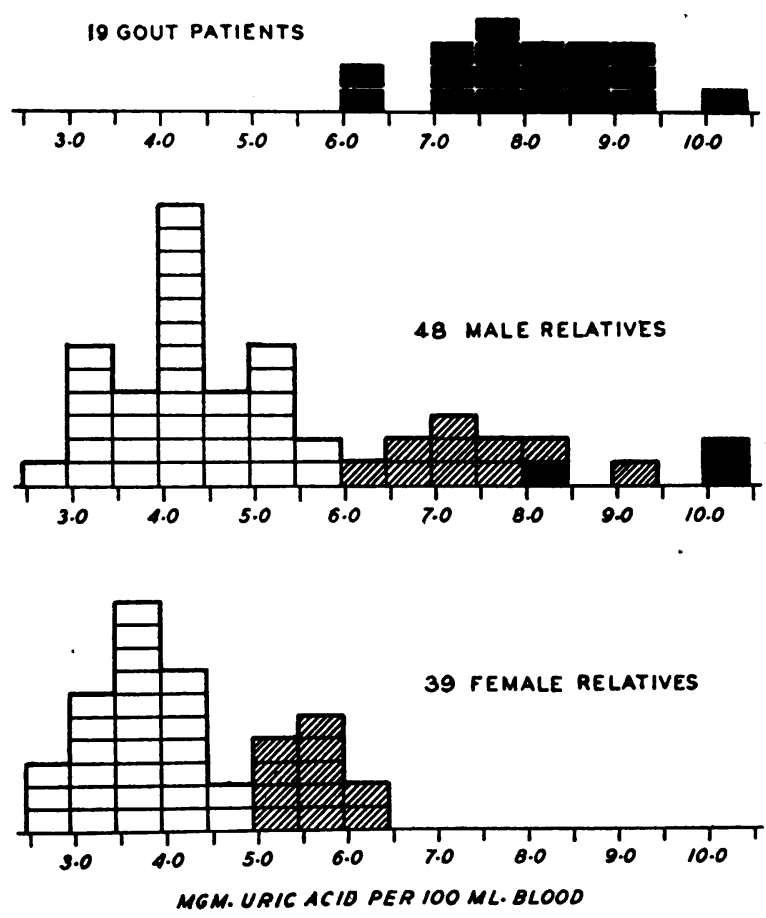

Fig. 3. Distribution of Serum Urate Levels in Gouty Patients and Relatives

Each block represents one individual. 
TABLE VII

Observed numbers of hyperuricemic $(H)$ and normal $(N)$ children among offspring of various matings

\begin{tabular}{l|c|c|c|c}
\hline \multicolumn{1}{c|}{ Matings } & \multicolumn{2}{|c|}{$\begin{array}{c}\text { Sons } \\
\text { omitting } \\
\text { propositi }\end{array}$} & \multicolumn{2}{|c}{ Daughters } \\
\cline { 2 - 5 } & $\begin{array}{c}\text { Over } \\
16 \text { yr. } \\
\text { H:N }\end{array}$ & $\begin{array}{c}\text { Under } \\
\text { 16 yr. } \\
\text { H:N }\end{array}$ & $\begin{array}{c}\text { Over } \\
\text { 16 yr. } \\
\text { H:N }\end{array}$ & $\begin{array}{c}\text { Under } \\
16 \text { yr. } \\
\text { H:N }\end{array}$ \\
\hline (A) $\begin{array}{l}\text { Gouty fathers } X \text { hyper- } \\
\text { uricemic mothers }\end{array}$ & $4: 0$ & - & $1: 0$ & - \\
\hline (B) $\begin{array}{l}\text { Gouty or hyperuricemic } \\
\text { fathers X normal or un- } \\
\text { tested mothers }\end{array}$ & $3: 7$ & $0: 12$ & $0: 4$ & $2: 3$ \\
\hline (C) $\begin{array}{l}\text { Normal or untested } \\
\text { fathers } X \text { hyperuricemic } \\
\text { mothers }\end{array}$ & $3: 0$ & $0: 2$ & $2: 2$ & $0: 1$ \\
\hline Total, (B) + (C) & $6: 7$ & $0: 14$ & $2: 6$ & $2: 4$ \\
\hline
\end{tabular}

An enumeration of the children arising from various matings having at least one hyperuricemic parent gives rise to Table VII. In constructing this table, allowance was made for the fact that those sibships which contain the original patient or propositus are biased in favor of hyperuricemic members. The propositus in each case must therefore be omitted. For example, in enumerating the children of a hyperuricemic woman, such as the mother of $\mathrm{S}$, the patient $\mathrm{S}$ is omitted and only his sibs are counted, thus giving two hyperuricemic sons, two hyperuricemic daughters, and two normal daughters. Similarly, patient $\mathrm{R}$, whose mother is hyperuricemic, is not counted, because having served as the propositus, it follows that he was necessarily gouty, and therefore, with high probability, hyperuricemic. On the other hand, all of I's children are counted since this sibship was brought to light not through one of the hyperuricemic sons, but through I himself. A fuller explanation of this procedure will be found elsewhere $(13,14)$.

Discounting those matings in which both parents are hyperuricemic, the remaining sibships contain six hyperuricemic and 21 normal sons. This constitutes a significant departure from the expected $1: 1$ ratio. However, when sons below 16 years of age are omitted, the ratio becomes six hyperuricemic: seven normal sons. Thus the data concerning male relatives are in agreement with the hypothesis of dominant autosomal inheritance if one assumes that the metabolic change resulting in hyperuricemia is one which is not manifested in males until about the age of puberty.

Among daughters in the same series of matings (Table VII) four are classed as hyperuricemic, 10 normal. This small number of observations is insufficient to show whether heterozygous females can be regularly distinguished from normal females by their serum urate levels. There is no suggestion here of an age difference in females similar to that found in males. However, it is possible that such may exist, for it is stated by Stecher and Hersh (7) that "hyperuricemia occurs with nearly ten times the normal frequency in brothers, sisters and sons, but not in daughters of gouty patients." 4 In Talbott's study (5) males and females were classified alike, using $6.0 \mathrm{mgm}$. per cent as the criterion for hyperuricemia, and the results show a significantly higher proportion of hyperuricemic males (27 out of 79) than hyperuricemic females (seven out of 57). The serum urate levels of these seven females were also lower than those characteristic of hyperuricemic males, viz., $6.2,6.2,6.4,6.7,7.0,7.0$, and $10.7 \mathrm{mgm}$. per cent.

The detection of heterozygous female relatives by means of their urate concentrations is a difficult one, and it may be questioned whether any significant success has been achieved by classifying as hyperuricemic those females having urate levels exceeding $5.0 \mathrm{mgm}$. per cent. More specifically, we may ask whether the 11 females thus classified are distributed among the 19 pedigrees in a man-

TABLE VIII

Female relatives classified according to their probabilities of possessing the abnormal gene

\begin{tabular}{c|c|c|c|c}
\hline \hline Female relatives & $\begin{array}{c}\text { Probability of possessing } \\
\text { abnormal gene as judged } \\
\text { from male relatives }\end{array}$ \\
\cline { 2 - 5 } & $P=1$ & $P=1$ & $P=1$ & $P=0$ \\
\hline $\begin{array}{l}\text { Hyperuricemic }(U>5.0 \text { mgm. } \%) \\
\text { Normal }\end{array}(U<5.0$ mgm. \%) & 0 & 7 & 0 & 1 \\
\hline
\end{tabular}

4 In a full report of their genetic studies now in press (Ann. Int. Med.), Stecher, Hersh, and Soloman report the finding of a significantly increased incidence of hyperuricemic female relatives beyond the age of menopause. No age effect in males was noted, but their series includes only a few relatives under 20 years of age. The possibility that hyperuricemia becomes most evident in males at puberty and in females at menopause is interesting in the light of hormonal studies of Wolfson et al. (see below). 
ner better suited to the hypothesis of a dominant gene than would be the case for any 11 females taken at random among the 39 females tested. Table VIII shows that this is apparently the case. In this table each tested female is classified according to her probability, $P$, of possessing the abnormal gene, such probability being inferred from the distribution of hyperuricemic males in her pedigree. For example, on the assumption that all males who are heterozygous have been correctly identified, it is certain (i.e., $P=1$ ) that any woman whose son is hyperuricemic and whose husband is not, is herself heterozygous. Of the three females thus judged to be heterozygous (Table VIII, column 2) all occur in the hyperuricemic range. For the eight unrelated wives of the propositi, the probability of possessing the relatively rare gene for hyperuricemia approaches $P=0$, and only one of these is hyperuricemic. For most of the remaining female relatives the probability of heterozygosity is approximately $P=1 / 2$, and in this group we find an intermediate ratio: seven hyperuricemic among a total of 26 . The proportion $7 / 26$, however, is significantly less than the expected proportion, $P=1 / 2$. It is therefore probable that some heterozygous females are not detectable, even when a liberal reduction in the critical level for hyperuricemia is made. Although no case occurs in our material wherein a gouty patient possesses parents both of whom were found to have normal blood uric acid levels, such might therefore be expected, particularly when the hereditary factor was derived from the mother.

Because gouty arthritis occurs much more frequently in males than in females, Talbott (15) has suggested that the responsible genetic factor may be sex-linked. This is made unlikely by the common occurrence of gouty or hyperuricemic sons of gouty male patients, as is seen in the two families illustrated in Talbott's paper (5), as well as in several families in our own series and in the studies of Stecher and Hersh (see above). Under sex-linked inheritance one would also expect higher average urate levels, or a higher incidence of hyperuricemia, among daughters of hyperuricemic males than among daughters of hyperuricemic females. Our data (Table VII) give no suggestion of such a difference.

\section{DISCUSSION}

In this paper we have attempted to explain the inheritance of essential hyperuricemia and gout as due to a dominant autosomal (i.e., not sex-linked) gene. Being relatively rare, this gene occurs in a small proportion of males and females who are heterozygous for it; that is, in individuals who have inherited the abnormal factor from only one parent. There is no evidence to suggest what the primary biochemical or developmental effect of this gene may be. We may say only that its presence in the heterozygous condition is detectable in a large percentage of cases by an elevated uric acid level in the blood, and in a much smaller percentage of cases, by clinical symptoms of gout. In discussing the genetics of gouty arthritis and hyperuricemia, care must be taken to distinguish these two states, and our discussion will first deal with hyperuricemia per se.

The proportions of hyperuricemic relatives to be expected if heterozygotes were invariably affected are approached when one makes allowances for the factors of age and sex. Reasonably good agreement is obtained in our material by lowering the critical level for hyperuricemia from $6.0 \mathrm{mgm}$. per cent in males to $5.0 \mathrm{mgm}$. per cent in females, and by discarding all male children under 16 years of age. The first of these corrections seems to be justified by a well-established difference in the serum urate levels of normal adult males and females, although the deduction of a full milligram may prove to be excessive. The second correction is based wholly on our own data. Classifying males and females separately there still appears to be a deficiency of hyperuricemic relatives, but this is conspicuous only among the relatives making up the final generations in the pedigrees (Figure 1). The deficiency is no longer apparent among the males when children under 16 years of age are excluded. Such a result is commonly observed in pedigrees of retinitis pigmentosa, muscular dystrophy, and numerous other dominantly inherited diseases that have a late age of onset of symptoms.

Concerning the age factor Talbott (5) states: "It is believed that this [hyperuricemia] is a manifestation of a familial tendency. If this assumption is correct, it is probable that an increased concentration is present at birth or shortly thereafter, although the youngest age observed by us was 14." 
Only three of the 34 relatives classed as hyperuricemic in Talbott's study were under 18 years of age, these being males aged $14 \mathrm{yr} ., 17 \mathrm{yr}$. and 17 yr., having urate levels of $6.4,6.6$ and $7.0 \mathrm{mgm}$. per cent, respectively. It therefore seems likely that Talbott's data would give evidence of an age effect in males similar to that observed in our material. The finding that marked hyperuricemia is rare before puberty does not, of course, exclude the possibility that a less pronounced elevation may be present, in which case a genetic classification of children might still be feasible. Statistical studies of urate levels in normal subjects of all ages are thus greatly needed for the further study of the genetic carriers in this disease.

Of the 24 hyperuricemic relatives in our study only three were found to have gouty arthritis, and all of these were members of the somewhat unusual family P. Obviously such data throw little or no light on the question as to what factors, in addition to hyperuricemia, may be necessary for the production of clinical gout. However, it would seem worthwhile to point out that the two chief peculiarities which have long been known regarding gout-its predilection for males and its occurrence in middle life-are strikingly paralleled by the facts regarding urate levels of the genetic carriers. If, given the presence of other necessary conditions, the probability of gouty symptoms increases with the absolute level of hyperuricemia reached and with the duration of this condition, then at least a partial explanation would seem to be offered by the differences in the serum urate levels themselves. Thus, the relative infrequency of gouty arthritis in women might be attributed in part to the fact that the abnormal gene, although occurring as frequently in females as in males, has a smaller average effect in elevating the urate level in this sex. This, added to the lower normal urate level in females, results in a much less pronounced degree of hyperuricemia in most of the female carriers. Similarly, the fact that gouty arthritis is principally a disease of middle age is enforced by the finding that marked hyperuricemia is apparently not reached in affected males until about the age of puberty. These "explanations" do not, of course, exclude the existence of other factors which may be important in the production of gouty symptoms and which are wholly unrelated to changes in the urate concentration of the blood. The fact that other provocative factors are necessary for gouty arthritis is argued by most workers in this field. In this connection, a recent report of Wolfson and co-workers (16) is of interest. These authors found a markedly reduced excretion of 17-ketosteroids in patients with gout, but not in patients having non-gouty hyperuricemia.

We may briefly mention one complication which arises in connection with the theory of inheritance which we have proposed. If we assume that a single dominant gene is necessary for hyperuricemia and gout, it is evident that this gene must be considerably more frequent in the general population than one might suspect from the incidence of gouty arthritis. In our study only three gouty relatives were found among 24 relatives classed as hyperuricemic. In Talbott's study three were found among 34 hyperuricemic relatives. The sex and age distributions of the relatives in these two studies do not differ markedly from those of the general population. Combining the two series, we may take $6 / 58$ or $1 / 10$ as an estimate of the proportion of heterozygotes of all ages who, at any given time, will manifest clinical gout. Among patients visiting arthritis clinics, our own experience agrees with that of other workers in showing that about 4 per cent are victims of gout. Assuming that gout occurs with the same frequency among that fraction of civilians (viz., 2.2 per cent) who are found in health surveys (17) to have histories of "chronic arthritis and rheumatism," we would judge the incidence of gout to be $0.04 \times 0.022$ or 88 per 100,000 . The frequency of all persons carrying the gene for hereditary hyperuricemia would thus be estimated to be $10 \times 0.00088$ or 0.88 per cent. In this calculation the figure 0.00088 is probably too large, since arthritis clinic patients may represent a selected group with respect to gout. On the other hand, the factor 10 , taken as the ratio of total carriers to gouty persons, is probably too small, since a considerable number of asymptomatic carriers (especially young males, and females in Talbott's data) have not been detected as hyperuricemic. The two errors may therefore tend to compensate one another in the product.

Taking 0.88 per cent as the frequency of heterozygotes, we should expect matings between two heterozygous individuals to occur with a frequency 
of $(0.0088)^{2}$ or about 8 per 100,000 , and the frequency of homozygotes would be one-quarter of this value, or about 2 per 100,000 . Now, it is known that certain so-called dominant genes in man are not completely dominant, but produce a more severe abnormality in the homozygous state $(1,2)$, and it is suspected that such may be the case for many pathological genes. If it were true of the gene for hyperuricemia, and if homozygotes were invariably gouty at an early age, while heterozygotes were only occasionally (1/10) afflicted, we should expect these two forms of gout to occur in the ratio $2 / 100,000: 88 / 100,000$, or 1 homozygous case to 44 heterozygous cases.

Furthermore, if homozygous gouty patients were more severely affected than heterozygous patients, such persons would be more likely to visit special clinics and serve as the propositi for family investigations. Unless the homozygous condition were lethal in early intrauterine life and therefore unobservable, it seems likely that homozygotes should make up a small, but appreciable, proportion of the clinical cases. Such cases might be expected to show earlier and more severe manifestations, as in a patient described by Ludwig, Bennett and Bauer (18). Both parents would be expected to be hyperuricemic, although neither would necessarily have symptomatic gout. As in the case of rare recessive abnormalities, such cases would be expected to arise with greater probability from consanguineous matings. With the estimated frequency of 2 per 100,000, homozygous patients would perhaps be found to have parents related as first cousins in about 5 to 10 per cent of cases (cf. Dahlberg [19]).

It is interesting that patient $\mathrm{P}$ in the present series of families has both parents in the hyperuricemic range according to our classification. One or more members of his sibship might therefore be homozygous, and indeed all of these affected brothers showed rather early ages of onset of acute attacks (6). One might also think of modifying environmental or genetic factors in interpreting families $G$ and $P$. In any event, biochemical tests on both parents in all branches of a family might be expected to throw considerable light on the above-mentioned questions. This is a defect in our investigation which should be remedied as far as possible in future studies.

\section{SUMMARY}

Data are presented on 87 relatives of 19 gouty male patients. Hyperuricemia in these families is apparently due to a single autosomal dominant gene, but only a portion of the heterozygotes for this factor develop recognized gouty arthritis. Sex and age are also significant factors affecting the level of serum urate, and these factors must be taken into account in classifying relatives into "normal" and "hyperuricemic" groups. Males who possess the abnormal hereditary factor apparently seldom develop marked hyperuricemia before the age of puberty. When males under 16 years of age are disregarded, the proportions of hyperuricemic male relatives approach those expected on the assumption that heterozygotes are invariably hyperuricemic. By reducing the critical level for hyperuricemia from $6.0 \mathrm{mgm}$. per cent in males to $5.0 \mathrm{mgm}$. per cent in females, the proportions of hyperuricemic females still fall somewhat short of the expected values.

The data are consistent with the view that gouty arthritis may develop in an individual of either sex who possesses sufficiently elevated serum urate level for sufficient time, this being less probable in heterozygous females owing to a lower normal level in women and to a lessened effect of the pathological gene in this sex. It is shown that the gene for essential hyperuricemia must be considerably more common than one might suspect from the incidence of clinical gout, and that homozygotes for this gene should therefore be observed occasionally.

\section{BIBLIOGRAPHY}

1. Neel, J. V., The clinical detection of the genetic carriers of inherited disease. Medicine, 1947, 26, 115.

2. Gates, R. R., Human Genetics. Vols. I and II, Macmillan, New York, 1946.

3. Garrod, A. E., The Inborn Factors in Disease. Oxford Press, New York, 1931.

4. Jacobson, B. M., Uric acid in serum of gouty and non-gouty individuals; its determination by Folin's recent method and its significance in the diagnosis of gout. Ann. Int. Med., 1938, 11, 1277.

5. Talbott, J. H., Serum urate in relatives of gouty patients. J. Clin. Invest., 1940, 19, 645.

6. Smyth, C. J., and Freyberg, R. H., A study of the hereditary nature of gout; a report of two families. Ann. Int. Med., 1942, 16, 46. 
7. Stecher, R. M., and Hersh, A. H., The inheritance of human gout or the incidence of familial hyperuricemia. Genetics, 1945, 30, 24.

8. Folin, O., Standardized methods for the determination of uric acid in unlaked blood and in urine. J. Biol. Chem., 1933, 101, 111.

9. Snedecor, G. W., Statistical Methods Applied to Experiments in Agriculture and Biology. Collegiate Press, Ames, Iowa, 1937.

10. Wright, S., Coefficients of inbreeding and relationship. Am. Naturalist, 1921, 56, 330.

11. Brøchner-Mortensen, K., Uric Acid in Blood and Urine. Levin \& Munksgaard, Copenhagen, 1937.

12. Bulger, H. A., and Johns, H. E., The determination of plasma uric acid. J. Biol. Chem., 1941, 140, 427.

13. Cotterman, C. W., Relatives ánd human genetic analysis. Scient. Monthly, 1941, 53, 227.

14. Fisher, R. A., The effects of methods of ascertain- ment upon the estimation of frequencies. Ann. Eugenics, 1934, 6, 13.

15. Talbott, J. H., Gout. Oxford Press, New York, 1943.

16. Wolfson, W. Q., Levine, R., Guterman, H. S., Hunt, H. D., Cohn, C., and Rosenberg, E. F., Endocrine factors in nucleoprotein metabolism and in gout. I. Preliminary biochemical and hormonal data. Proc. Am. Rheumat. Assn., in press.

17. Collins, S. D., Causes of illness in 9,000 families, based on nation-wide periodic canvasses, 1928-31. Pub. Health Rep., 1933, 48, 283.

18. Ludwig, A. O., Bennett, G. A., and Bauer, W., A rare manifestation of gout; widespread ankylosis simulating rheumatoid arthritis. Ann. Int. Med., 1938, 11, 1248.

19. Dahlberg, G., Mathematische Erblichkeitsanalyse von Populationen. Acta Med. Scand., Suppl. 148, 1943, pp. 219. 